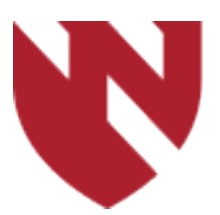

September 2020

\title{
Thiamine Supplementation Does Not Improve Outcomes in Hospitalized Patients with Encephalopathy
}

\author{
Daniel J. Zhou \\ University of Nebraska Medical Center \\ Navya Joseph \\ University of Nebraska Medical Center \\ Kaeli Samson \\ University of Nebraska Medical Center \\ Matthew Purbaugh \\ University of Nebraska Medical Center \\ Brian Villafuerte-Trisolini \\ University of Nebraska Medical Center
}

See next page for additional authors

Tell us how you used this information in this short survey.

Follow this and additional works at: https://digitalcommons.unmc.edu/gmerj

Part of the Higher Education Commons, and the Medicine and Health Sciences Commons

\section{Recommended Citation}

Zhou, D. J., Joseph, N., Samson, K., Purbaugh, M., Villafuerte-Trisolini, B., Kodali, N., , Kedar, S. Thiamine Supplementation Does Not Improve Outcomes in Hospitalized Patients with Encephalopathy. Graduate Medical Education Research Journal. 2020 Sep 29; 2(1).

https://digitalcommons.unmc.edu/gmerj/vol2/iss1/34

This Conference Proceeding is brought to you for free and open access by DigitalCommons@UNMC. It has been accepted for inclusion in Graduate Medical Education Research Journal by an authorized editor of DigitalCommons@UNMC.For more information, please contact digitalcommons@unmc.edu. 
Thiamine Supplementation Does Not Improve Outcomes in Hospitalized Patients with Encephalopathy

\section{Creative Commons License}

\section{(c) (1) $\Theta(9$}

This work is licensed under a Creative Commons Attribution-Noncommercial-No Derivative Works 4.0 License.

\section{Authors}

Daniel J. Zhou, Navya Joseph, Kaeli Samson, Matthew Purbaugh, Brian Villafuerte-Trisolini, Neeharica Kodali, and Sachin Kedar 
behavior and failure patterns in H\&N may be different from trunk/extremity, supporting consideration of dedicated $\mathrm{H} \& \mathrm{~N}$ trial.

https://doi.org/10.32873/unmc.dc.gmerj.2.1.032
Table 1.

$+S L N$ group demonstrates higher rate of local (LR), nodal (LNR), and systemic (SR) recurrence, as well as higher rate of death due to disease (DOD) when compared with -SLN group. Within +SLN group, patients who underwent complete lymph node dissection (CLND) surprisingly have higher rate of LR, LNR, SR, and DOD.

\begin{tabular}{lccccccc}
$\begin{array}{l}\text { Completed SLNBx } \\
\text { (N= 108) }\end{array}$ & LR \% & LNR \% & $\begin{array}{c}\text { Local/Regional } \\
\text { recurrence } \%\end{array}$ & SR \% & $\begin{array}{c}\text { Combined } \\
\text { Sys/Nodal } \%\end{array}$ & DOD \% & NED \% \\
\hline SLN -ve (77) & $18 \%$ & $8 \%$ & $21 \%$ & $13 \%$ & $1 \%$ & $7 \%$ & $93 \%$ \\
\hline SLN +ve (31) & $23 \%$ & $32 \%$ & $35 \%$ & $45 \%$ & $29 \%$ & $29 \%$ & $55 \%$ \\
CLND (20) & $\mathbf{3 5 \%}$ & $\mathbf{4 5 \%}$ & $\mathbf{5 5 \%}$ & $55 \%$ & $40 \%$ & $35 \%$ & $45 \%$ \\
+SLNBx only (11) & $\mathbf{0 \%}$ & $\mathbf{9} \%$ & $\mathbf{9} \%$ & $27 \%$ & $9 \%$ & $18 \%$ & $73 \%$ \\
p-value & $\mathbf{0 . 0 3 *}$ & $\mathbf{0 . 0 5 5}$ & $\mathbf{0 . 0 2 *}$ & 0.26 & 0.15 & 0.43 & 0.26 \\
\hline
\end{tabular}

\section{Thiamine Supplementation Does Not Improve Outcomes in Hospitalized Patients With Encephalopathy}

Daniel J. Zhou' ${ }^{1}$, Navya Joseph ${ }^{1}$, Kaeli Samson², Matthew Purbaugh'1, Brian Villafuerte-Trisolini', Neeharica Kodali ${ }^{3}$, Sachin Kedar ${ }^{1}$

${ }^{1}$ University of Nebraska Medical Center, Department of Neurological Sciences

${ }^{2}$ University of Nebraska Medical Center, College of Public Health, Department of Biostatistics

${ }^{3}$ University of Nebraska Medical Center, Electronic Health Record Data Access Core

Mentor: Sachin Kedar

Program: Neurology

Type: Original Research

Background: In hospitalized and critically ill patients, thiamine deficiency is common, difficult to clinically diagnose, and increases risk for encephalopathy.1,2 Thiamine supplementation for patients with encephalopathy has become routine at UNMC for its safety and potential benefits. We hypothesized that thiamine supplementation in hospitalized patients with encephalopathy would decrease their length of stay (LOS).

Methods: Adults (age $>19$ years) with index admission to UNMC between $1 / 1 / 2017$ and $12 / 31 / 2017$, hospital stay of 3-30 days, and ICD-10 code associated with encephalopathy were identified by the hospital electronic health record data access core. Primary outcome was hospital LOS, which we logtransformed due to skewness. Model adjusted mean $\log$ LOS estimates were exponentiated to obtain geometric means. Patients in the Thiamine group received at least one dose of supplemental thiamine (including multivitamins). A general linear model was used to evaluate the association between log LOS and thiamine supplementation.

Results: We identified 985 patients who met the above criteria. Table 1 describes the cohort demographics and clinical characteristics. After adjusting for potential confounding variables (denoted in Table 1), the mean $\log \operatorname{LOS}$ was 1.95 for the Thiamine group and 1.63 for the No Thiamine group (p $<0.0001)$.
Table 1.

Demographic and clinical characteristics of hospitalized patients with encephalopathy.

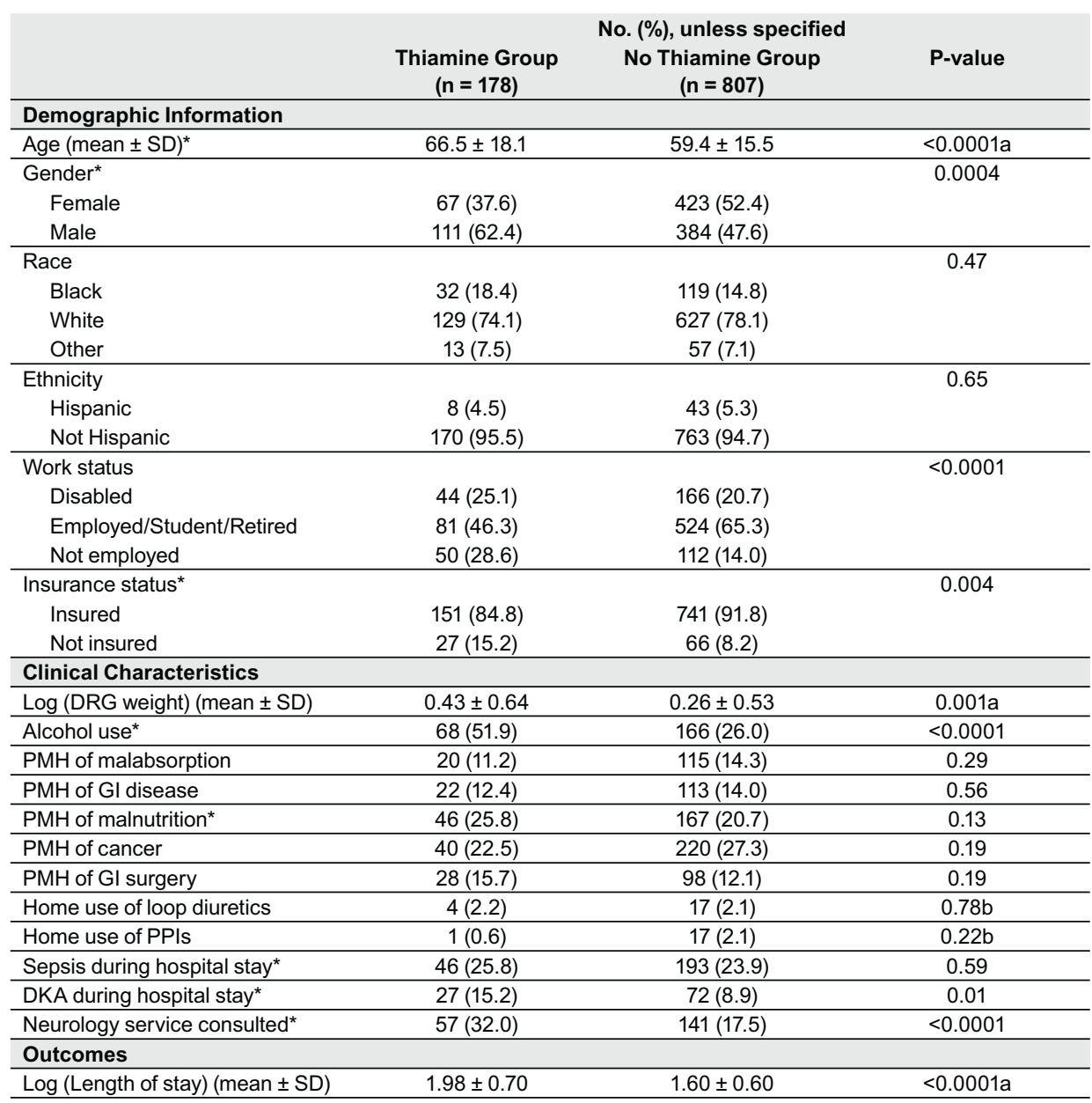

Abbreviations: $\mathrm{SD}=$ standard deviation. $\mathrm{DRG}=$ diagnosis-related group. $\mathrm{PMH}=$ past medical history $\mathrm{GI}=$ gastrointestinal. $\mathrm{DKA}=$ diabetic ketoacidosis. LOS $=$ length of stay.

P-values from Chi-Square tests, unless otherwise specified

a P-values from t-test. b P-values from Fisher's exact test.

* Potential confounding variables that can contribute to log (LOS) via linear model.

Demographic information, clinical characteristics, and primary outcome were compared between the Thiamine group and No Thiamine group. 
Conclusion: Contrary to prevailing expectations and our study hypothesis, we found that thiamine supplementation in hospitalized patients with encephalopathy did not improve LOS. Our results are consistent with the lack of beneficial effects of supplemental thiamine in other disease conditions such as sepsis (VITAMINS study) and congestive heart failure.3-5 We do not recommend routine thiamine supplementation in hospitalized patients.

\section{References}

1 Attaluri P, Castillo A, Edriss H, Nugent K. Thiamine Deficiency: An Important Consideration in Critically Ill Patients. Am J Med Sci. 2018;356(4):382-390.

2 Isenberg-Grzeda E, Kutner HE, Nicolson SE. Wernicke-Korsakoff-syndrome: under-recognized and under-treated. Psychosomatics. 2012;53(6):507-16

3 Fujii T, Luethi N, Young PJ, et al. Effect of vitamin $\mathrm{C}$, hydrocortisone, and thiamine vs hydrocortisone alone on time alive and free of vasopressor support among patients with septic shock: The VITAMINS randomized clinical trial. JAMA. 2020

https://doi.org/10.32873/unmc.dc.gmerj.2.1.033

\section{Acute Colonic Perforation in Renal Transplant Recipients: A Case Series Emily Zurbuchen ${ }^{1}$, Nathalie Sela ${ }^{2}$, Alexander Maskin ${ }^{1}$ ${ }^{1}$ University of Nebraska Medical Center, Department of Surgery \\ ${ }^{2}$ University of Nebraska Medical Center, Department of Surgery, Division of Transplantation Surgery}

Mentor: Alexander Maskin

Program: General Surgery

Type: Case Report

Introduction: There are few cases of nondiverticulitis episodes of colonic perforation following kidney transplantation throughout literature. In the systematic literature review by de'Angelis et al, emergency abdominal surgery following solid organ transplantation for non-diverticulitis causes gastrointestinal perforation accounts of $9.2 \%$ of cases, and about $58 \%$ of those perforations occurred in the colon. The aim of this case series is to review the events surrounding our two cases of colonic perforation following renal transplantation in hopes to gain understanding of this rare occurrence. Consent was obtained from the patients.

Case: Since 2011, there have been two events of transverse colonic perforation in the acute post-operative period following renal transplantation occurring at this institution. Large volume intraperitoneal air observed on plain film upon work up gastrointestinal symptoms prompted urgent surgical intervention in both cases. Both patients underwent urgent exploratory laparotomy and Hartmann procedure with resection of perforated transverse colon and proximal ostomy. The first patient underwent colostomy
4 Kattoor AJ, Goel A, Mehta JL. Thiamine therapy for heart failure: A promise or fiction? Cardiovasc Drugs Ther. 2018;32(4):313-317.

5 Smithline HA, Donnino M, Blank FSJ, et al. Supplemental thiamine for the treatment of acute heart failure syndrome: A randomized controlled trial. $B M C$ Complement Altern Med. 2019;19(1):96-019-2506-8.

\section{Proceedings of the 2nd Annual Graduate Medical Education Research Symposium | Poster Presentations}

\section{Does Prophylactic Administration of Tranexamic Acid Reduce Mean Operative Time and Perioperative Blood Loss in Posterior Cervical Spinal Fusion Surgery?}

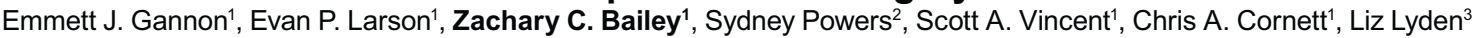

${ }^{1}$ University of Nebraska Medical Center, Department of Orthopaedic Surgery and Rehabilitation

${ }^{2}$ University of Nebraska Medical Center, College of Medicine

${ }^{3}$ University of Nebraska Medical Center, College of Public Health, Department of Biostatistics

Mentor: Chris Cornett

Program: Orthopaedic Surgery and Rehabilitation

Type: Original Research

Background: Adequate control of bleeding during spine surgery is paramount to the success and efficiency of the operation. Tranexamic acid (TXA) is a systemic antifibrinolytic that is beneficial in reducing blood loss during various orthopaedic procedures. TXA's role in posterior cervical spinal surgery, however, remains poorly described. Therefore we sought to evaluate whether prophylactic TXA administration prior to posterior cervical fusion reduces perioperative blood loss and mean operative time.

Methods: Patients undergoing three to six-level posterior cervical fusions were retrospectively enrolled into two groups. In the study group, 21 patients received TXA prior to surgery, and in the control group, 21 patients did not. Patient's younger than 19 years old, and those undergoing surgery for infection or tumors were excluded. Intraoperative blood loss, operative time, and postoperative drain output were measured in addition to demographic data.
Results: No difference existed between groups in regards to demographics. The study group had a lower mean operative time (94 min) vs the control group (110 $\mathrm{min})$, although not statistically significant $(\mathrm{p}=0.06071)$. Postoperative day 1 drain output was significantly lower in the study group $(\mathrm{p}<0.0239)$. Intraoperative blood loss, day 2, 3 and total drain output were lower in the study group but not statistically significant. There were two postoperative hematomas in the control group. No postoperative thromboembolic events occurred in either group. 